\title{
Preparation and characterization of porous granular ceramic containing dispersed aluminum and iron oxides as adsorbents for fluoride removal from aqueous solution
}

\author{
Nan Chen ${ }^{\mathrm{a}, \mathrm{b}}$, Zhenya Zhang ${ }^{\mathrm{b}}$, Chuanping Feng ${ }^{\mathrm{a}, *}$, Dirui Zhu ${ }^{\mathrm{b}, \mathrm{c}}$, Yingnan Yang ${ }^{\mathrm{b}}$, Norio Sugiura ${ }^{\mathrm{b}}$ \\ ${ }^{a}$ School of Water Resources and Environment, China University of Geosciences (Beijing), Beijing, \\ 100083, China \\ ${ }^{\mathrm{b}}$ Graduate School of Life and Environmental Sciences, University of Tsukuba, Tsukuba, 305-8572, \\ Japan \\ ${ }^{\text {c } S c h o o l ~ o f ~ L i f e ~ S c i e n c e s, ~ Y u n ~ N a n ~ U n i v e r s i t y, ~ Y u n n a n, ~ 650091, ~ C h i n a ~}$
}

\begin{abstract}
Porous granular ceramic adsorbents containing dispersed aluminum and iron oxides were synthesized by impregnating with salt solutions followed by precipitation at $600{ }^{\circ} \mathrm{C}$. In the present work detailed studies were carried out to investigate the effect of contact time, adsorbent dose, initial solution $\mathrm{pH}$ and co-existing anions. Characterisation studies on the adsorbent by SEM, XRD, EDS, and BET analysis were carried out to clarify the adsorption mechanism. The adsorbents were sphere in shape, 2 3 mm in particle size, highly porous and showed specific surface area of $50.69 \mathrm{sq} \mathrm{m} / \mathrm{g}$. The fluoride adsorption capacity of prepared adsorbent was $1.79 \mathrm{mg} / \mathrm{g}$, and the maximum fluoride removal was obtained at $\mathrm{pH}$ 6. Both the Langmuir and Freundlich isotherm models were found to represent the measured adsorption data well. The experimental data were well explained with pseudo-second-order kinetic model. Results from this study demonstrated potential utility of $\mathrm{Al} / \mathrm{Fe}$ dispersed in
\end{abstract}


porous granular ceramics that could be developed into a viable technology for fluoride removal from aqueous solution.

Keywords: Porous granular ceramic; Fluoride removal; Adsorption isotherms; Adsorption kinetics

*Correspondence: Chuanping Feng, School of Water Resources and Environment, China University of Geosciences (Beijing), Beijing, 100083, China.

Tel: +86 1082322281

Fax: +86 1082321081

E-mail: fengchuanping@gmail.com (C. Feng)

\section{Introduction}

Fluoride element is essential as well as detrimental for the dental and skeletal growth of human beings. Deposited fluoride contaminations are found in water mostly due to natural processes (e.g., geochemical reactions and volcanic emissions) and industrial activities (e.g., semiconductor, electroplating, steel and fertilizers industries) [1, 2]. The WHO recommended the tolerance limit for fluoride in drinking water is $1.5 \mathrm{mg} / \mathrm{L}$ [3]. It has been reported that higher fluoride concentrations in water can lead to various diseases (e.g., dental caries, skeletal fluorosis, osteoporosis and arthritis etc) [4, 5]. Moreover, some serious effects were also observed in different countries, such as India, Mexico, Africa and China [6-9]. For these reasons, the removal of the excess fluoride from water is important in terms of protection of public health and 
environment.

Existing methods to remove fluoride from water includes adsorption, ion exchange, membrane processing (such as reverse osmosis), Donnan dialysis, and electrodialysis [10-17]. Among these different traditional methods, adsorption is one of the most popular separation and purification method due to its high selectivity, low operating cost, easy handling and effective reducing quantity [18]. Several adsorbents were tried for the removal of fluoride from aqueous solution namely activated alumina, red mud, chitosan beads, carbonaceous materials, calcite, and hydrated cement [10, 19-23], etc. However, most of these adsorbents were not applicable in rural areas due to their financial and technological constraints. Therefore, it is desirable to develop a novel adsorbent which is robust, inexpensive, porous and able to effectively remove fluoride in subsequent operations and also can avoid clogging during field applications.

Due to its high electronegativity and small ionic size, the fluoride ion is classified as a hard base, which has a strong affinity towards metal ions including $\mathrm{Al}^{3+}$ and $\mathrm{Fe}^{3+}$ [24]. Dispersing a mixture of these metals in a porous material would limit the total dissolved solids in treated water as well as would provide high fluoride adsorption capacity [25]. Porous granular ceramics could be the good candidate to be a metal-support material due to its large surface area and continuous porosity structure. In the present study, we have successfully developed a new adsorbent by impregnation of porous granular ceramics with aluminum and iron salts to remove 
fluoride form aqueous solution. Batch studies are conducted using these novel adsorbents with optimization of various experimental conditions, including contact time, adsorbent dose, initial $\mathrm{pH}$ and co-existing ions in solutions. The nature and morphology of the adsorbents are therefore discussed on the basis of SEM, XRD, EDS, and BET studies. The Langmuir and Freundlich isotherm models are used to explain the mechanism of fluoride removal by these novel adsorbents. Various kinetic models are also included to describe the adsorption process.

\section{Experimental}

\subsection{Material preparation}

Knar clay (particle size was less than $75 \mu \mathrm{m}$ ) was purchased in the Isehisa Store (Japan), zeolite (particle size was less than $100 \mu \mathrm{m}$ ) was supplied by the Azuwan Cement Factory (Japan), wheat starch was supplied by the Wako Pure Chemical Industries, Ltd (Japan). Knar clay, zeolite and starch (with mass ratio 1:1:1) were mixed by ultra pure water (resistivity18.2 $\mathrm{M} \Omega \mathrm{cm}$ at $25{ }^{\circ} \mathrm{C}$ ) to prepare the porous granular ceramic based on simple co-precipitation method by manual. Detailed procedure was given in previous publication [11]. Then the prepared porous granular ceramics were impregnated in a boiling mixture of $1 \mathrm{M} \mathrm{AlCl} 3$ and $1 \mathrm{M} \mathrm{FeCl}$ a aqueous solution for $2 \mathrm{~h}$. After the heating, the samples remained to be immersed in the salt solution for $2 \mathrm{~h}$. The impregnated granules were removed from the solution, then exposed in the open air for $2 \mathrm{~h}$ and afterwards dried in an oven at $105^{\circ} \mathrm{C}$ for $24 \mathrm{~h}$. The obtained samples were calcined at $600^{\circ} \mathrm{C}$ for $1 \mathrm{~h}$ in a muffle furnace. Finally, samples 
were cooled to room temperature and transferred to airtight glass bottles for further study. The specific surface areas of adsorbents were determined by the BET method with $\mathrm{N}_{2}$ gas (Coulter SA3100, Japan). The mineralogy of supported metal-oxide was characterized by powder XRD techniques (Rigaku RINT2200, Japan). The surface morphology and spot elemental analysis of ceramic adsorbents were carried out using the scanning electron microscope (SEM) and energy dispersive X-ray spectroscopy (EDS) detector (JEOL, SEM-EDS-6700F, Japan), respectively.

\subsection{Adsorption experiments}

A stock solution (100 mg F/L) was prepared by dissolving $0.221 \mathrm{~g}$ anhydrous sodium fluoride in $1 \mathrm{~L}$ of ultra pure water. This was diluted to obtain the required concentration for further use. The fluoride adsorption experiments were carried out by a batch method at room temperature $\left(25 \pm 1^{\circ} \mathrm{C}\right)$. The $\mathrm{pH}$ of the fluoride solution in the experiment was adjusted using $0.1 \mathrm{M} \mathrm{NaOH}$ and $\mathrm{HCl}$ solutions. $100 \mathrm{~mL}$ of fluoride solution and $2 \mathrm{~g}$ of coated ceramic adsorbents were placed in a shaker at a speed of $100 \mathrm{rpm}$ (Tai Tec Thermo Minder Mini-80, Japan). The effect of experimental procedure for adsorption isotherms and kinetics, adsorption at different adsorbent dose, initial $\mathrm{pH}$ and interference of other co-existing anions has been described in a batch study. Fluoride analysis was carried out using a fluoride reagent spectrophotometer (Hach, DR/4000U, Japan) at $620 \mathrm{~nm}$ wavelength according to SPADNS (APHA, Standards Method for the Examination of Water and Waste Water, 1998) [26]. 


\section{Results and discussion}

\subsection{Characterization of adsorbent}

The prepared $\mathrm{Al} / \mathrm{Fe}$ dispersed in porous granular ceramic adsorbent is reddish brown colored and 2-3 mm in diameter (shown in Fig. 1b). As can be seen from Fig. 1a, the adsorbents have the expected large numbers of porous structures in the cross section which indicates the adsorbent may have a high adsorption capacity. This microcosmic pore texture can be attributed to the sintering of certain inorganic and organic substances (such as starch) during the calcination process. The EDS spectrum of Fig. 1e shows the presence of $\mathrm{Fe}, \mathrm{Al}, \mathrm{Si}, \mathrm{O}$ and $\mathrm{Cl}$ in the surface of adsorbent, which can be attributed to the impregnation process with $\mathrm{AlCl}_{3}$ and $\mathrm{FeCl}_{3}$ salt solutions. It is difficult to establish the accurate chemical composition of the inorganic compounds which were formed in granular ceramics, because of the possible existence of some amorphous compounds and the complexity of the knar clay. However, it appears that there would be mainly iron and aluminum oxides on the surface of ceramics. The chemical composition (oxides) of $\mathrm{Al} / \mathrm{Fe}$ dispersed in porous granular ceramic adsorbent that was determined by EDS is presented in Table 1. The XRD patterns of the ceramic adsorbents that contain iron and aluminum oxides are shown in Fig. 1c and Fig. 1d. It is observed from Fig. 1c that diffraction peaks attributed to crystalline iron oxide, aluminum oxide, hematite and maghemite. The peaks of $\mathrm{Fe}$ and $\mathrm{Al}$ in Fig. 1c are due to the granular ceramics coated by $\mathrm{AlCl}_{3}$ and $\mathrm{FeCl}_{3}$ salt solutions. It is clear that the crystal and amorphous structures of adsorbent had significantly changed after the adsorption process (Fig. 1d). The diffraction peaks are attributed to crystalline iron 
and aluminum fluoride hydroxide hydrate and iron zinc oxide fluoride. This may suggest that the uptake of fluoride ions is partly by chemical adsorption. The specific surface area of $\mathrm{Al} / \mathrm{Fe}$ dispersed in porous granular ceramic adsorbent (Table 1) further confirmed its porous nature. The specific surface area of ceramic adsorbent is found to be $50.69 \mathrm{sq} \mathrm{m} / \mathrm{g}$, and the pore volume is $0.1108 \mathrm{ml} / \mathrm{g}$. The pore-size distributions (Fig. 1f) indicate that the observed pore sizes mostly varied between 6 and $80 \mathrm{~nm}$ (73.23\%). As the radius of fluorine (1.33 $)$ is much smaller than this value $(6 \sim 80 \mathrm{~nm})$, which may increase the possibility of $\mathrm{F}^{-}$ions dispersing into the inner layer of the granular adsorbents.

Table 1

Chemical analysis and surface area characterization of $\mathrm{Al} / \mathrm{Fe}$ dispersed in porous granular ceramics.

Fig. 1. SEM images of (a) cross section of pristine granular ceramics and (b) Photo of pristine granular ceramics, Powder XRD patterns of (c) pristine granular ceramics and (d) adsorbed granular ceramics, EDS spectra of (e) pristine granular ceramics, BJH (Barrett-Joyner-Halenda) pore-size distribution of (f) pristine granular ceramics.

\subsection{Effect of adsorbent dose}

The effect of adsorbent dose on the fluoride removal was studied at $\mathrm{pH} 6.9 \pm 0.1$, room temperature and $10 \mathrm{mg} / \mathrm{L}$ of fluoride. The results obtained are shown as percent adsorption and loading capacity in Fig. 2a. It was observed that the percentage removal of fluoride increased from $69.4 \%$ to $95.7 \%$ with an increase in adsorbent dose from 10 to $30 \mathrm{~g} / \mathrm{L}$. However, after a dose of $20 \mathrm{~g} / \mathrm{L}$, the amount removed per unit 
of adsorbent declined. The increase in fluoride removal with increase of adsorbent dose is the consequence of a greater amount of available binding sites for fluoride. The distribution coefficient $\left(K_{\mathrm{D}}\right)$ for fluoride on adsorbent was calculated by [27]:

$K_{D}=\left[F^{-}\right]_{a d s} /\left[F^{-}\right]_{\text {diss }}\left(1 / C_{p}\right)$

where $C_{\mathrm{p}}$ is the solid concentration in $\mathrm{kg} / \mathrm{L}$ and $K_{\mathrm{D}}$ has the units of $\mathrm{L} / \mathrm{kg}$. A distribution coefficient reflects the binding ability of the surface for an element. The $K_{\mathrm{D}}$ value of a system mainly depends on $\mathrm{pH}$ and the type of surface. It was found that the $K_{\mathrm{D}}$ values increased with increase of adsorbent dose (Fig. 2b), which is very similar to the results investigated by Sujana et al. [28]. It is clearly revealed the binding ability of the surface, as reflected in the $K_{\mathrm{D}}$ values, decreased with the adsorbent dose increased. If the surface is homogeneous the $K_{\mathrm{D}}$ value should not change with adsorbent dose at constant $\mathrm{pH}$, so the increase of $K_{\mathrm{D}}$ values indicated the heterogeneous in nature of adsorbent surface [28, 29].

Fig. 2. (a) Effect of prepared adsorbent dose variation on fluoride removal (Initial $\mathrm{pH} 6.9 \pm 0.1$, initial fluoride concentration $10 \mathrm{mg} / \mathrm{L}$, equilibrium contact time $48 \mathrm{~h}$ and temperature $25 \pm 1{ }^{\circ} \mathrm{C}$ ). (b) The plot of $\log K_{\mathrm{D}}$ value as a function of prepared adsorbent dose (data corresponding to (a)).

\subsection{Effect of solution $\mathrm{pH}$}

Fig. 3. (a) Effect of initial $\mathrm{pH}\left(\mathrm{pH}_{\mathrm{i}}\right)$ variation on fluoride removal (Adsorbent dose $20 \mathrm{~g} / \mathrm{L}$, initial fluoride concentration $10 \mathrm{mg} / \mathrm{L}$, equilibrium contact time $48 \mathrm{~h}$ and temperature $25 \pm 1^{\circ} \mathrm{C}$ ). (b) The variation of final $\mathrm{pH}\left(\mathrm{pH}_{\mathrm{f}}\right)$ against initial $\mathrm{pH}\left(\mathrm{pH}_{\mathrm{i}}\right)$.

The initial $\mathrm{pH}$ of solution is one of the important parameters that could obviously 
affect the extent of fluoride adsorption. As shown in Fig. 3a, the amount of adsorbed fluoride enhances significantly with increasing $\mathrm{pH}$ and it attains a maximum at $\mathrm{pH}$ 6, thereafter it declines. The maximum fluoride removal was found to be $89.3 \%$, with a fluoride adsorption capacity of $0.4464 \mathrm{mg} / \mathrm{g}$. Fig. 3b demonstrates the variation of equilibrium $\mathrm{pH}\left(\mathrm{pH}_{\mathrm{f}}\right)$ from the initial $\mathrm{pH}\left(\mathrm{pH}_{\mathrm{i}}\right)$ during experiments. Horizontal portion at $\mathrm{pH}_{\mathrm{f}}$ ranged in 6.5-6.6 should be the $\mathrm{pH}_{\mathrm{zpc}}$ of prepared adsorbent. Therefore, the surface characteristic of the mixed oxide is (i) positive at $\mathrm{pH}_{\mathrm{f}}<6.5$, (ii) neutral at $\mathrm{pH}_{\mathrm{f}}$ = 6.5-6.6, and (iii) negative at $\mathrm{pH}_{\mathrm{f}}>6.6$.

The mechanism involved in the fluoride adsorption process using $\mathrm{Al} / \mathrm{Fe}$ dispersed in porous granular ceramics can be described by the following equations, where $\mathrm{M}$ is $\mathrm{Al}^{3+}$ and $\mathrm{Fe}^{3+}$ bound to porous granular ceramics.

$$
\begin{aligned}
& \mathrm{MCl}_{(\mathrm{s})}+\mathrm{H}_{2} \mathrm{O} \rightarrow \mathrm{MOH}_{(\mathrm{s})}+\mathrm{H}_{(\mathrm{aq})}^{+}+\mathrm{Cl}_{(\mathrm{aq})}^{-} \\
& \mathrm{MOH}_{(\mathrm{s})}+\mathrm{H}_{3} \mathrm{O}_{(\mathrm{aq})}^{+}+\mathrm{F}^{-} \rightarrow \mathrm{MOH}_{2}^{+} \cdots \mathrm{F}_{(\mathrm{s})}^{-}+\mathrm{H}_{2} \mathrm{O} \\
& \mathrm{MOH}+\mathrm{F}^{-}+\mathrm{H}_{3} \mathrm{O}^{+} \rightarrow \mathrm{M}^{+} \ldots \mathrm{F}_{(\mathrm{a})}^{-}+2 \mathrm{H}_{2} \mathrm{O}
\end{aligned}
$$

It was evident from our results that the granular ceramics exhibited significantly fluoride removal in the acidic $\mathrm{pH}$ range (the fluoride removal is $86.7 \%$ at $\mathrm{pH} 4$, which is similar to the maximal value $89.3 \%$ at $\mathrm{pH}$ 6). This may be due to the fact that for $\mathrm{pH}_{\mathrm{i}}<\mathrm{pH}_{\mathrm{zpc}}$, the positive adsorbent surface adsorbed fluoride with electrostatic force of attraction (Eqs.3) or by exchange of hydroxyl ion on the solid surface (Eqs.4). The minimal fluoride removal at $\mathrm{pH}<4$ may be attributed to the formation of $\mathrm{HF}$, which 
would reduce the coulombic attraction between fluoride and the adsorbent surface [1] The decrease in the amount of fluoride adsorbed at $\mathrm{pH}>6$ is probably due to competition for adsorption sites between fluoride and hydroxyl ions even though the oxide surface is positively charge [30]. The mechanism as suggested are found to be similar to that had been reported for fluoride adsorption by iron (III)-aluminum (III)-chromium (III) ternary mixed oxide [31], concrete materials [32] and activated cerium (IV) oxide/SiMCM-41 adsorbent [33].

\subsection{Effect of co-existing anions}

The fluoride-contaminated water may contain several other anions which may compete with fluoride ions in the adsorption process. The present study assessed fluoride adsorption behavior in the presence of $200 \mathrm{mg} / \mathrm{L}$ chloride, nitrate, sulfate, carbonate, and phosphate ions, with initial fluoride concentration of $10 \mathrm{mg} / \mathrm{L}$. As can be seen from Fig. 4, it was observed that carbonate and phosphate showed extremely negative effect, nitrate showed slightly positive effect while chloride and sulfate really did not affect the fluoride removal. The slight increase in fluoride removal in the presence of nitrate ion could be due to an increase in the ionic strength of the solution or a weakening of lateral repulsion between adsorbed fluoride ions. While the carbonate and phosphate ions decreased the fluoride adsorption may attributed to the high coulombic repulsive forces, which reduce the probability of fluoride interactions with the active sites. Besides, the $\mathrm{pH}$ of the fluoride solutions was $6.15,6.45,6.57$, 10.34 and 10.78, respectively, for $\mathrm{Cl}^{-}, \mathrm{NO}_{3}{ }^{-}, \mathrm{SO}_{4}{ }^{2-}, \mathrm{CO}_{3}{ }^{2-}$ and $\mathrm{PO}_{4}{ }^{3-}$, while the initial 
$\mathrm{pH}$ of the fluoride solution was 6.9 without the addition of salt/anions. It was also confirmed from the experiment on the effect of $\mathrm{pH}$ (Section 3.3), that fluoride removal decreases in highly alkaline $\mathrm{pH}$. Similar observations have been reported by Eskandarpour et al. and Kagne et al. [34, 23].

Fig. 4. Effect of co-existing anions on fluoride removal (Adsorbent dose $20 \mathrm{~g} / \mathrm{L}$, initial fluoride concentration $10 \mathrm{mg} / \mathrm{L}$, equilibrium contact time $48 \mathrm{~h}$ and temperature $25 \pm 1^{\circ} \mathrm{C}$ )

\subsection{Adsorption isotherms}

The distribution of fluoride ion between the liquid and solid phase is a measure of the position of equilibrium in the adsorption process which can be expressed by the Freundlich and Langmuir isotherm models.

\section{Table 2}

Langmuir and Freundlich isotherm parameters for the adsorption of fluoride on $\mathrm{Al} / \mathrm{Fe}$ dispersed in porous granular ceramics.

Freundlich equation is derived to model the multilayer adsorption and for the adsorption on heterogeneous surfaces. The linearized form of Freundlich model is formulated as [35]:

$\log q_{e}=\log k_{F}+1 / n \log C_{e}$

where $C_{\mathrm{e}}$ is equilibrium concentration, $q_{\mathrm{e}}$ is equilibrium adsorption capacity, $K_{\mathrm{F}}$ and $1 / n$ are Freundlich constants, related to minimum adsorption capacity and adsorption intensity, respectively. The values of $K_{\mathrm{F}}$ and $1 / n$ were obtained from the slope and intercept of the linear Freundlich plot of $\log q_{\mathrm{e}}$ versus $\log C_{\mathrm{e}}$, and the results were 
shown in Table 2. It was found that the value of adsorption intensity $(1 / n=0.468)$ is less than unity, which indicates favorable in the fluoride adsorption process [36].

Langmuir adsorption isotherm models the monolayer coverage of the adsorption surfaces and assumes that adsorption take places on a structurally homogeneous surface of the adsorbent. The linear form of the Langmuir model can be presented as [37]:

$1 / q_{e}=1 /\left(q_{\max } b C_{e}\right)+1 / q_{\max }$

where $C_{\mathrm{e}}$ is the concentration of fluoride at equilibrium, $q_{\mathrm{e}}$ is the adsorption capacity at equilibrium, $q_{\max }$ is the monolayer capacity of the adsorbent and $b$ is the Langmuir adsorption constant. The values of Langmuir parameters, $q_{\max }$ and $b$ were calculated from the slope and intercept of the linear plots of $1 / q_{\mathrm{e}}$ versus $1 / C_{\mathrm{e}}$ and were found to be $1.788 \mathrm{mg} / \mathrm{g}$ and $0.313 \mathrm{~L} / \mathrm{mg}$ respectively, with regression coefficient $\left(R^{2}\right)$ of 0.995 .

The essential characteristic of the Langmuir isotherm can be denoted by the dimensionless constant called equilibrium parameter, $R_{\mathrm{L}}$, defined by [38]

$R_{\mathrm{L}}=1 /\left(1+b c_{0}\right)$

where $b$ is the Langmuir constant and $C_{0}$ is the initial fluoride concentration $(\mathrm{mg} / \mathrm{L})$. The value of $R_{\mathrm{L}}<1$ represents favorable adsorption and $R_{\mathrm{L}}>1$ represents unfavorable adsorption [39]. The value of $R_{\mathrm{L}}$ for an initial fluoride concentration of $10 \mathrm{mg} / \mathrm{L}$ is found to be 0.242 , which indicates that this system is favorable for adsorption. 


\subsection{Adsorption kinetics}

\section{Table 3}

Kinetics parameters for adsorption of fluoride onto $\mathrm{Al} / \mathrm{Fe}$ dispersed in porous granular ceramics.

The effect of contact time was studied up to $72 \mathrm{~h}$ at initial fluoride concentration of 10 $\mathrm{mg} / \mathrm{L}$, adsorbent dose of $20 \mathrm{~g} / \mathrm{L}$, initial solution $\mathrm{pH}$ of 6.9 , temperature of $25^{\circ} \mathrm{C}$. The results showed that loading capacity was $0.4464 \mathrm{mg} / \mathrm{g}$, and the equilibrium was attained within $48 \mathrm{~h}$. According to the kinetic data obtained from the experiments, pseudo-first-order and pseudo-second-order kinetic models were used to elucidate the mechanisms of adsorption and potential rate controlling steps [40, 41].

$\log \left(q_{e}-q_{t}\right)=\log q_{e}-k_{1} t / 2.303$

$t / q_{t}=1 /\left(k_{2} q_{e}^{2}\right)+t / q_{\theta}$

where $q_{\mathrm{t}}$ and $q_{\mathrm{e}}$ are the amount of adsorbed fluoride $(\mathrm{mg} / \mathrm{g})$ at time $t$ and at equilibrium time, respectively. $k_{1}$ and $k_{2}$ are first-order and second-order rate constants for adsorption. The adsorption rate constant $k_{1}$ was determined from the slope of the linear plot of $\log \left(q_{\mathrm{e}}-q_{\mathrm{t}}\right)$ versus $\mathrm{t}$ (Fig. 5a), and $k_{2}$ was obtained by plotting $t / q_{\mathrm{t}}$ versus $\mathrm{t}$ (Fig. 5b). The adsorption kinetic constants obtained from the pseudo-first and pseudo-second order models are shown in Table 3. The kinetic data indicates that the fluoride adsorption on $\mathrm{Al} / \mathrm{Fe}$ dispersed in porous granular ceramics obeys the pseudo-second order kinetic model $\left(R^{2}=0.995\right)$ more than pseudo-first order kinetic model $\left(R^{2}=0.975\right)$, which suggests a chemisorption process in this experiment.

The possible contribution of intra-particle diffusion on fluoride adsorption process 
was described by using Weber-Morris model. The linear form of intra-particle diffusion model is given by [42]

$q_{\mathrm{t}}=k_{\mathrm{i}} t^{1 / 2}+C$

where $k_{\mathrm{i}}$ can be calculated from the slope of the plot of $q_{\mathrm{t}}$ versus $t^{1 / 2}$. As shown in Fig. 5c, the linear portion of plot is not passing through the origin, which indicates the fluoride adsorption on $\mathrm{Al} / \mathrm{Fe}$ dispersed in porous granular ceramics is a complex procedure. Both the surface adsorption as well as intra-particle diffusion contributes to the rate determining step $[28,38]$. Since the pore size of adsorbent is larger than fluorine radius (section 3.1), it is conductive to the penetration of $\mathrm{F}^{-}$ion inside the pore structure of granular ceramic adsorbents.

Fig. 5. (a) Pseudo-first-order kinetic plot for fluoride removal. (b) Pseudo-second-order kinetic plot for fluoride removal. (c) Intra-particle diffusion plot for fluoride removal. (Adsorbent dose 20 $\mathrm{g} / \mathrm{L}$, initial pH $6.9 \pm 0.1$, initial fluoride concentration $10 \mathrm{mg} / \mathrm{L}$, equilibrium contact time $48 \mathrm{~h}$ and temperature $25 \pm 1^{\circ} \mathrm{C}$ )

\subsection{Adsorbent recoating}

Regeneration of any exhausted adsorbent is a crucial factor in any sorption process for improving the process economics. In the present study, $0.1 \mathrm{M} \mathrm{HCl}$ and $\mathrm{NaOH}$ were used as an eluent to check its eluting potential. From the results, it was observed that 0.1 M HCl could elute nearly 85\% adsorbed fluoride from porous granular ceramics. Then the adsorption study was carried out using $20 \mathrm{~g} / \mathrm{L}$ fluoride-desorbed adsorbents with initial fluoride concentration of $10 \mathrm{mg} / \mathrm{L}$. The results showed that a considerable reduction in adsorption efficiency after the regeneration, which may be attributed to 
the gradual dissolution of coated layer from the surface during vigorous washing of the adsorbent. Hence, a new recycle protocol was developed by recoating the exhausted adsorbent before adsorption. For this, after desorption process using $0.1 \mathrm{M}$ $\mathrm{HCl}$, the exhausted granular ceramic adsorbents were dipped in $1 \mathrm{M} \mathrm{AlCl}_{3}$ and $\mathrm{FeCl}_{3}$ solutions for 2-3 h. The mixture were dried and calcined at $600{ }^{\circ} \mathrm{C}$ and used for next adsorption cycle. After the adsorption experiment, it was found that adsorption efficiency of adsorbent after recoating was no reduction.

\section{Conclusion}

In the present study, $\mathrm{Al}$ and Fe dispersed in porous granular ceramics were prepared by the impregnation with aluminum and iron chloride salts followed by a precipitation process. These low-cost adsorbents showed a good efficiency in fluoride removal from aqueous solution and could be useful for environmental protection purposes. The loading capacity of these prepared adsorbents for fluoride was $1.79 \mathrm{mg} / \mathrm{g}$ at room temperature. The optimum fluoride removal was observed at $\mathrm{pH}$ ranges of 4.0-9.0 indicating that the adsorbent has promising potential utility in practical application. Carbonate and phosphate ions showed extremely negative effect, nitrate ion showed slightly positive effect while chloride and sulfate ions really did not affect the fluoride removal capacity. The adsorption process was fitted well with both the Freundlich and Langmuir isotherm models. Kinetic study results indicated that the adsorption process followed a pseudo-second-order kinetic model. Therefore, the elaborated porous granular ceramics with mixed aluminum and iron oxides have a good potential by 
promising environmental materials for fluoride removal from aqueous solution.

\section{Acknowledgements}

The authors thank Development of Catch-Up Type Ceramics Material with Higher Pollutant Removal Efficiency and Its Application to Water Renovation of JST, the National Key Technology R\&D Program in the 11th Five year Plan of China (2006BAJ08B04, 2006BAD01B03), 863 Project (2007AA06Z351) for the financial support of this work.

\section{References}

[1] M.G. Sujana, R.S. Thakur, S.B. Rao, Removal of fluoride from aqueous solution by using alum sludge, J. Colloid and Inter. Sci. 206 (1998) 94-101.

[2] A. Toyoda, T. Taira, A new method for treating fluorine wastewater to reduce sludge and running costs, IEEE Trans. Semiconduct. Manufact. 13 (2000) 305-309.

[3] WHO, Guidelines for Drinking Water Quality, World Health Organization, Geneva 45 (1993).

[4] Meenakshi, V.K. Garg, Kavita, Renuka, A. Malik, Groundwater quality in some villages of Haryana, India: focus on fluoride and fluorosis, J. Hazard. Mater. 106 (2004) 85-97.

[5] E.I. Reardon, Y. Wang, A limestone reactor for fluoride removal from wastewaters, Environ. Sci. Technol. 34 (2000) 3247-3253.

[6] G. Jacks, P. Bhattacharya, V. Chaudhary, K.P. Singh, Controls on the genesis of 
some high-fluoride groundwater in India, Appl. Geochem. 20 (2005) 221-228.

[7] J.J. Carrillo-Rivera, A. Cardona, W.M. Edmunds, Use of abstraction regime and knowledge of hydrogeological conditions to control high-fluoride concentration in abstracted groundwater: San Luis Potosi basin, Mexico, J. Hydrol. 261 (2002) 24-47.

[8] B. Gizaw, The origin of high bicarbonate and fluoride concentrations in waters of the main Ethiopian Rift Valley, J. Afr. Earth Sci. 22 (1996) 391-402.

[9] Ministry of Health of the People's Republic of China, Chinese Health Statistical Digest (2007) http://www.moh.gov.cn/open/2007tjts/P50.htm.

[10] A. Tor, N. Danaoglu, G. Arslan, Y. Cengeloglu, Removal of fluoride from water by using granular red mud: Batch and column studies, J. Hazard. Mater. 164 (2009) 271-278.

[11] N. Chen, Z.Y Zhang, C.P. Feng, N. Sugiura, M. Li, R.Z. Chen, Fluoride removal from water by granular ceramic adsorption, J. Colloid and Inter. Sci. 348 (2010) 579-584.

[12] M. Shihabudheen, Maliyekkal, S. Sanjay, P. Ligy, M.N. Indumathi, Enhanced fluoride removal from drinking water by magnesia-amended activated alumina granules, J. Eng. Chem. 140 (2008) 183-192.

[13] G. Singh, B. Kumar, P.K. Sen, J. Majumdar, Removal of fluoride from pot liner leachate using ion exchange, Water Environ. Res. 71 (1999) 36-42.

[14] S.V. Joshi, S.H. Mehta, A.P. Rao, A.V. Rao, Estimation of sodium fluoride using HPLC in reverse osmosis experiments, Water Treat. 10 (1992) 307-312.

[15] A. Tor, Removal of fluoride from water using anion-exchange membrane under 
Donnan dialysis condition, J. Hazard. Mater. 141 (2007) 814-818.

[16] M. Hichour, F. Persin, J. Sandeaux, J. Molenat, C. Gavach, Water defluoridation by donnan dialysis and electrodialysis, Rev. Sci. Eau. 12 (1999) 671-686.

[17] M. Zeni, R. Riveros, K. Melo, R. Primieri, S. Lorenzini, Study on fluoride reduction in artesian well-water from electrodialysis process, Desalination. 185 (2005) 241-244.

[18] P. King, N. Rakesh, S. Beenalahari, Y.P. Kumar, V.S.R.K. Prasad, Removal of lead from aqueous solution using Syzygium cumini L.: equilibrium and kinetic studies, J. Hazard. Mater. 142 (2007) 340-347.

[19] S. Ghorai, K.K. Pant, Equilibrium, kinetics and breakthrough syudies for adsorption of fluoride on activated alumina, Sep. Purif. Technol. 42 (2005) 265-271.

[20] N. Viswanathan, C.S. Sundaram, S. Meenakshi, Removal of fluoride from aqueous solution using protonated chitosan beads, J. Hazard. Mater. 161 (2009) 423-430.

[21] A. Ikuo, I. Satoshi, T. Toshimitsu, K. Naohito, N. Takeo, T. Seiki, Adsorption of fluoride ions onto carbonaceous materials, J. Colloid and Inter. Sci. 275 (2004) 35-39. [22] M. Yang, T. Hashimoto, N. Hoshi, H, Myoga, Fluoride removal in a fixed bed packed with granular calcite, Water Res. 33 (1999) 3395-3402.

[23] S. Kagne, S. Jagtap, P. Dhawade, S.P. Kamble, S. Devotta, S.S. Rayalu, Hydrated cement: a promising adsorbent for the removal of fluoride from aqueous solution, J. Hazard. Mater. 154 (2008) 88-95.

[24] X. Wu, Y. Zhang, X. Dou, M. Yang, Fluoride removal performance of a novel 
Fe- Al-Ce trimetal oxide adsorbent. Chemosphere. 69 (11) (2007) 1758-1764.

[25] T.K. Eric, A. Véronique, C.P. Nanseu-Njiki, A. Nathalie, N. Emmanuel, D. André, Preparation and characterization of charcoals that contain dispersed aluminum oxide as adsorbents for removal of fluoride from drinking water, Carbon. 48 (2010) 333-343.

[26] Water and Wastewater Monitoring Analysis Method (Fourth edition), China Environmental Science Press. 4 (2002) 193-195.

[27] J.W. Murray, W. Stumm (Ed.), Aquatic surface chemistry: Chemical processes at the particle-water interface, John Wiley \& Sons, New York, 52 (1988) 1742.

[28] M.G. Sujana, S. Anand, Iron and aluminum based mixed hydroxides: A novel sorbent for fluoride removal from aqueous solutions, Applied Sur. Sci. 256 (2010) 6956-6962.

[29] W.J. Moore, Magnetic field effects on the excitation spectra of neutral group II double acceptors in germanium, J. Phys and Chem. Solids. 32 (1971) 93-102.

[30] A.M. Raichur, M.L. Basu, Adsorption of fluoride onto rare earth oxides. Sep Purif Technol. 24 (1-2) (2001) 121-127.

[31] K. Biswas, K. Gupta, A. Goswami, U.C. Ghosh, Fluoride removal effeiciency from aqueous solution by synthetic iron (III)-aluminum (III)-chromium (III) ternary mixed oxide, Desalination. 255 (2010) 44-51.

[32] E. Oguz, Adsorption of fluoride on gas concrete materials, J. Hazard. Mater. B117 (2005) 227-233.

[33] Y.M. Xu, A.R. Ning, J. Zhao, Preparation and defluoridation performance of 
activated cerium (IV) oxide/SiMCM-41 adsorbent in water, J. Colloid and Inter. Sci. 235 (2001) 66-69.

[34] A. Eskandarpour, M.S. Onyango, A. Ochieng, Removal of fluoride ions from aqueous solution at low pH using schwertmannite, J. Hazard. Mater. 152 (2008) 571-579.

[35] H.M.F. Freundlich, Über die adsorption in losungen, Z. Phys. Chem. 57A (1906) 385-470.

[36] S. Ghorai, K.K. Pant, Investigations on the column performance of fluoride adsorption by activated alumina in a fixed bed, Chem. Eng. J. 98 (2004) 165-173.

[37] I. Langmuir, The constitution and fundamental properties of solids and liquids, J. Am. Chem. Soc. 38 (1916) 2221-2295.

[38] M. Mahramlioglu, I. Kizilicilii, I.O. Bicer, Adsorption of fluoride from aqueous solution by acid treated spent bleaching earth, J. Fluorine Chem. 115 (2002) 41-47.

[39] M. Arami, N.Y. Limaee, N.M. Mahmoodi, N.S. Tabrizi, Removal of dyes from colored textile wastewater by orange peel adsorbent: equilibrium and kinetic studies, J. Colloid and Inter. Sci. 288 (2005) 371-376.

[40] I.B. Solangi, S. Memon, M.I. Bhanger, An excellent fluoride sorption behavior of modified amberlite resin, J. Hazard. Mater. 176 (2010) 186-192.

[41] P. Chutia, S. Kato, T. Kojima, S. Satokawa, Arsenic adsorption from aqueous solution on synthetic zeolites, J. Hazard. Mater. 162 (2009) 440-447.

[42] W.J. Weber Jr, J.C. Morris, Kinetics of adsorption on carbon from solution, J. Sanit. Eng. Div. ASCE. 89 (1963) 31-59. 